\title{
Notice of Retraction
}

After careful and considered review of the content of this paper by a duly constituted expert committee, this paper has been found to be in violation of IEEE's Publication Principles.

We hereby retract the content of this paper. Reasonable effort should be made to remove all past references to this paper.

The presenting author of this paper has the option to appeal this decision by contacting TPII@ieee.org. 


\title{
Study on Optimized-select Model of Investment Decision in the Electric Project Based on Grey Comprehensive Related Degree
}

\author{
LIU Jian-yong ${ }^{1}$ ，ZHI Jun ${ }^{1,2}$ ， YU Jing ${ }^{2}$, JING Le ${ }^{2}$ ， DU Hai-lu ${ }^{2}$ \\ 1 PLA University of Science and Technology; 2 Zhengjiang Watercraft College
}

\begin{abstract}
It puts forward and uses the method to improve grey related analysis in the investment decision of the electric project, introduces the concept of the theory of the gray target, sets up comprehensive difference matrix in order to improve the sensitivity and accuracy of the scheme optimum seeking while calculating. Then it fixes every index weight through membership degree, and then calculates and arranges in an order to the weighted average comprehensive value. It can offer the optimized-select scheme for investment decision of the electric project according to its appraisal result.
\end{abstract}

Keywords-electric project; weight; grey comprehensive related degree

\section{I.INTRODUCTION}

At present, the investment decision - making of electric project in our country, the commonly used method are net present value method, inside earning ratio, risk that adjust the law of discount rate, affirm the law in the coefficient law of equivalent, payback period of investment etc. These methods are only limited to the overall investment of the decision project of less indexes, unilateral, do not have an overall result of project investment that can be overall to think. The project investment of power construction has the characteristic such as large capital cost, many financing channels, the capital source is complicated, the mode of investment is various, being longer in payback period of investment, the decision fault will cause enormous losses to enterprise. So the paper has proposed a decision method that using many indexes comprehensive in the investment decision of the electric project in order to evade the risk effectively. The method forms the index system with net present value, inside earning ratio, risk degree, payback period of investment.

\section{II.THE OPTIMIZED-SELECT MODEL}

\section{A. Question description}

We assume that $X=\left\{x_{1}, x_{2}, \cdots, x_{n}\right)$ is the collect for the scheme of each kind of electric project investment. $f_{i j}=f_{i}\left(x_{j}\right)$ and $f_{i j}$ is the expression for the index value of number $i$ in the scheme $x_{j}$.

According to the factor influencing capital project, $f_{j}=f\left(x_{j}\right)=\left(f_{1}\left(x_{j}\right), f_{2}\left(x_{j}\right), f_{3}\left(x_{j}\right), f_{4}\left(x_{j}\right)\right)=\{$ Net present value (NPV), inside earning ratio, risk degree, payback period of investment .

(1)and(2) are straight indexes, it is the better that index value is the higher, (3)and(4) go against by index, the lower the better. When it needs to turn against the index into the straight index with the grey related analytical method, the risk degree is turned into $(1-\mathrm{Q})$, and the payback period of investment is turned into $\mathrm{l} / \mathrm{T}$.

\section{B. Grey fuzzy membership degree}

Grey related analysis is a kind of multifactor statistics analytical method. It is based on sample data of every factor, it describes the power of the dependence among the factors with grey related degree. If it is basically unanimous to the situation change among the factor that the sample array reflects, then related degree between them is relatively big. On the contrary, related degree is relatively small.

The index value of different capital projects forms the comparative array with grey related analysis. It is $f_{i}(i=1,2, \cdots, m)$. Compared with the index value of the scheme, it must structure a reference array, that is $f_{0}$. The paper uses comprehensive related degree method so there are two kind reference arrays. Every attribute index is respectively the optimum value or the worst value of corresponding index in all schemes available, the index arrays signifying the ideal scheme are $f_{0}$ and $f_{0}^{\prime}$. 
When judging the index value, we should have the dimension treatment and measure yardstick in unison first usually, so as to ensure the judge is equivalently. Its treatment method is finished from the leaving type.

$T\left(f_{i}\left(x_{j}\right)\right)=\frac{\min \left\{f_{i}\left(x_{0}\right), f_{i}\left(x_{j}\right)\right\}}{\max \left\{f_{i}\left(x_{0}\right), f_{i}\left(x_{j}\right)\right\}}$

What it showed is its reached degree that index value is relative to ideal index value, and it forms the normal ideal reference array.

$T\left(f_{i}\left(x_{0}\right)\right)=\left\{T\left(f_{1}\left(x_{0}\right)\right), T\left(f_{2}\left(x_{0}\right)\right) ; \cdots ; T\left(f_{m}\left(x_{0}\right)\right)\right\}=(1,1, \cdots ; 1)_{1 \times m} \quad$ Form the following matrix (2) from the comparative array and the reference array:

$\left(f_{0}, f_{1}, \cdots f_{n}\right)=\left[\begin{array}{cccc}f_{1}\left(x_{0}\right) & f_{1}\left(x_{1}\right) & \cdots & f_{1}\left(x_{n}\right) \\ f_{2}\left(x_{0}\right) & f_{2}\left(x_{1}\right) & \cdots & f_{2}\left(x_{n}\right) \\ \vdots & \vdots & \cdots & \vdots \\ f_{m}\left(x_{0}\right) & f_{m}\left(x_{1}\right) & \cdots & f_{m}\left(x_{n}\right)\end{array}\right]_{m \times(n+1)}$

We can derive the following difference matrixes as (3) and

from the

formula

$\Delta_{0 j}(i)=\left|T\left(f_{i}\left(x_{0}\right)\right)-T\left(f_{i}\left(x_{j}\right)\right)\right|=\mid 1-T\left(f_{i}\left(x_{j}\right) \mid\right.$.

Optimum difference matrix:

$\left[\begin{array}{cccc}\Delta_{01}(1) & \Delta_{02}(1) & \cdots & \Delta_{0 n}(1) \\ \Delta_{01}(2) & \Delta_{02}(2) & \cdots & \Delta_{0 n}(m) \\ \vdots & \vdots & \cdots & \vdots \\ \Delta_{01}(m) & \Delta_{02}(m) & \cdots & \Delta_{0 n}(m)\end{array}\right]_{m \times n}$

Worst difference matrix:

$\left[\begin{array}{cccc}\mathcal{E}_{01}(1) & \mathcal{E}_{02}(1) & \cdots & \mathcal{E}_{0 n}(1) \\ \mathcal{E}_{01}(2) & \mathcal{E}_{02}(2) & \cdots & \mathcal{E}_{0 n}(m) \\ \vdots & \vdots & \cdots & \vdots \\ \mathcal{E}_{01}(m) & \mathcal{E}_{02}(m) & \cdots & \mathcal{E}_{0 n}(m)\end{array}\right]_{m \times n}$

We can derive the following comprehensive difference matrix (5) from the formula $\alpha_{o j}(i)=\frac{1}{\left(1+\Delta_{01 j} / \varepsilon_{01 j}\right)^{2}}$.

Comprehensive difference matrix:

$$
\left[\begin{array}{cccc}
\alpha_{01}(1) & \alpha_{02}(1) & \cdots & \alpha_{0 n}(1) \\
\alpha_{01}(2) & \alpha_{02}(2) & \cdots & \alpha_{0 n}(m) \\
\vdots & \vdots & \cdots & \vdots \\
\alpha_{01}(m) & \alpha_{02}(m) & \cdots & \alpha_{0 n}(m)
\end{array}\right]_{m \times n}
$$

Situation that the comprehensive difference matrix produced like this has not merely prevented the result from being distorted when calculate the membership degree matrix, and it has reached higher sensitivity. It has higher precision compared with the comprehensive related degree method adopted in [2]. The changes of every index value between different schemes will influence the optimized-select result of the capital project.

Write separately as formula (6).

$$
\operatorname{maxmax}_{i} \alpha_{0 j}(i)=\operatorname{maxmax}_{i}\left(\frac{1}{\left(1+\Delta_{01 j} / \varepsilon_{01 j}\right)^{2}}\right)
$$

$\operatorname{minmin}_{j} \alpha_{0 j}(i)=\operatorname{minmin}_{j}\left(\frac{1}{\left(1+\Delta_{01 j} / \varepsilon_{01 j}\right)^{2}}\right)$

Carry on the related analysis between the comparative array and ideal reference array. We can receive the related coefficient of the index value to the ideal value in the scheme.

Thus given the calculation formula of the grey related coefficient promptly the membership degree after improving as follows.

$$
\left.\chi f_{i}\left(x_{0}\right), f_{i}\left(x_{j}\right)\right)=\frac{\operatorname{mimina}_{i} a_{0 j}(i)-\xi_{j} \operatorname{maxmax}_{i} a_{0 j}(i)}{\alpha_{0 j}(i)+\xi \operatorname{maxmax}_{j} \alpha_{0 j}(i)}
$$

In formula (7), $0 \leq \xi \leq 1, \xi$ is distinguishing parameter, its value is usually set as 0.5 . Formula(7) means that considering the possible influence between every index value to scheme number $j$ in all available schemes, this scheme may reach the degree of the ideal scheme as regards the index value $i$. We name it grey fuzzy membership degree about index $f_{i}$ to scheme $x_{j}$, that is $\gamma_{i}\left(x_{j}\right)$, note by abridging as $\gamma_{i j}$, so the membership degree matrix $\gamma$ is $\gamma=\left(\gamma_{i j}\right)_{m \times n}$.

\section{The weight vector quantities of indexes}

Write $S=\left(s_{1}, s_{2}, \cdots, s_{m}\right)$ as the weight vector 
quantity of the index, and $\sum_{i=1}^{m} s_{i}=1, s_{i}>0$. Because the weight information of the ${ }_{i=1}^{\text {index }}$ has not been fixed in advance, so some weight has been known in the weight vector quantity, some weight is the unknown and is undetermined . We can assume that the preceding $p(p \geq 1)$ index weight is unknown, and the last $m-p$ weight is known. That is $s_{i}=s_{i}^{*} \geq 0, \sum_{i=p+1}^{m} s_{i}^{*}<1$, where $i=p \dashv 1, p \dashv 2, \cdots, m$. Define it as follows.

$$
\begin{aligned}
& S^{0}=\left(s_{1}^{\prime}, s_{2}^{\prime}, \cdots, s_{p}^{\prime}\right)^{T} \\
& S^{\prime}=\left(S^{0}, s_{p+1}^{*}, s_{p+2}^{*}, \cdots, s_{m}^{*}\right)^{T} \\
& d=1-\sum_{i=p+1}^{m} s_{i}^{*}, \quad c=1-\sum_{i=p+1}^{m} s_{i}^{* 2}
\end{aligned}
$$

So we can get the weighted average comprehensive value

$$
\text { of the }
$$

scheme

$x_{j} \in X \cdot \rho_{j}\left(S^{\prime}\right)=\sum_{i=1}^{m} s_{i}^{\prime} \gamma_{i j}(j=1,2, \cdots, n)$

Obviously for the given weight vector quantity $W^{\prime}$, the larger the weighted average comprehensive value $\rho_{j}\left(S^{\prime}\right)$ is, the better the $x_{j}$ is. So we can establish the indexes decision model expressed in formula (9).

$$
\text { s.t. }\left\{\begin{array}{l}
\sum_{i=1}^{p} s_{i}^{\prime 2}=c \\
s_{i}^{\prime} \geq 0(i=1,2, \cdots, p)
\end{array}\right.
$$

Because every scheme is fair, they have the same importance. So we can concentrate the decision-making questions of above-mentioned many indexes as the equivalent non-linear planning problem below with equal weight.

$$
\begin{aligned}
& \max \left\{h\left(S^{\prime}\right)=\frac{1}{n} \sum_{j}^{n} \rho_{j}\left(S^{\prime}\right)\right\} \\
& \text { s.t. }\left\{\begin{array}{l}
\sum_{i=1}^{p} s_{i}^{\prime 2}=c \\
s_{i}^{\prime} \geq 0(i=1,2, \cdots, p)
\end{array}\right.
\end{aligned}
$$

Solve the above-mentioned model and we can get the weight of the index.

$$
s_{i}^{\prime}=\sqrt{c / \sum_{i=1}^{p}\left(\sum_{j=1}^{n} \gamma_{i j}\right)^{2}} \sum_{j=1}^{n} \gamma_{i j}
$$

And we will have the standardized type as follows.

$$
s_{i}^{*}=d \sum_{j=1}^{n} \gamma_{i j} /\left(\sum_{i=1}^{p} \sum_{j=1}^{n} \gamma_{i j}\right)
$$

Thus try to get the weight vector quantity of the index.

$$
S^{*}=\left(s_{1}^{*}, s_{2}^{*}, \cdots, s_{m}^{*}\right)
$$

\section{D. optimized-select model of the scheme}

If we have already confirmed the weight vector quantity of every influence factor is $s=\left(s_{1}, s_{2}, \cdots, s_{m}\right)^{T}$, and the membership degree matrix. We can get the weighted average comprehensive value of the scheme $\rho_{j}\left(S^{\prime}\right)=\sum^{m} s_{i}^{\prime} \times \gamma\left(f_{i}\left(x_{0}\right), f_{i}\left(x_{j}\right)\right)$

So we can carry on the sequencing of the good and bad degree of capital project according to the size of $\rho_{j}\left(S^{\prime}\right)$. The order of the scheme is preceding when $\rho_{j}\left(S^{\prime}\right)$ is larger.

\section{III.INSTANCE ANALYSES}

There are 3 kind capital projects of $\mathrm{A}, \mathrm{B}$ and $\mathrm{C}$, the capital cost is respectively 500 million, 750 million and 800 million yuan. It is estimated that the cash the flow material is tab 1 .

\begin{tabular}{|c|c|c|c|c|c|c|}
\hline \multicolumn{7}{|c}{ Tab.1 Estimated cash flows } \\
\hline \multirow{2}{*}{ Year } & A scheme & \multicolumn{2}{c|}{ B scheme } & \multicolumn{2}{c|}{ C scheme yuan } \\
\cline { 2 - 7 } & NOC & P & NOC & P & NOC & P \\
\hline 0 & -50000 & & -75000 & & -80000 & \\
\hline 1 & 15000 & 0.5 & 10000 & 0.6 & 0 & 0.6 \\
\hline \multirow{2}{*yyyyyyy}{} & 25000 & 0.5 & 20000 & 0.4 & 10000 & 0.4 \\
\hline 2 & 20000 & 0.7 & 20000 & 0.7 & 10000 & 0.5 \\
\hline & 30000 & 0.3 & 30000 & 0.3 & 20000 & 0.5 \\
\hline 3 & 30000 & 0.7 & 30000 & 0.4 & 30000 & 0.5 \\
\hline & 40000 & 0.3 & 40000 & 0.6 & 40000 & 0.5 \\
\hline 4 & 30000 & 0.4 & 40000 & 0.7 & 50000 & 0.6 \\
\hline & 40000 & 0.6 & 50000 & 0.3 & 60000 & 0.4 \\
\hline 5 & 25000 & 0.6 & 50000 & 0.8 & 70000 & 0.5 \\
\hline & 30000 & 0.4 & 60000 & 0.2 & 80000 & 0.5 \\
\hline 6 & 25000 & 0.8 & 40000 & 0.6 & 60000 & 0.6 \\
\hline & 30000 & 0.2 & 50000 & 0.4 & 70000 & 0.4 \\
\hline
\end{tabular}

NOC: Net flow of the cash, P: Probility

The relevant indexes of different schemes is as tab 2 . 
Tab.2 Indices of different schemes

\begin{tabular}{|c|c|c|c|c|}
\hline Index & NPV & $\begin{array}{c}\text { Inside earn } \\
\text {-ing ratio }\end{array}$ & $\begin{array}{c}\text { Risk } \\
\text { degree }\end{array}$ & $\begin{array}{c}\text { Payback } \\
\text { period }\end{array}$ \\
\hline A & 71115.9 & 33.29 & 0.0697 & 2.2121 \\
\hline B & 71928.0 & 31.95 & 0.0551 & 3.0267 \\
\hline C & 81905.4 & 30.18 & 0.0610 & 3.4815 \\
\hline
\end{tabular}

Based on above-mentioned results, 3 kind schemes are all in acceptable range. Which one is the best, it needs to make the choice. If compare with some individual event index, we will draw contradictory conclusions, so it is clear to introduce the method of grey comprehensive related degree.

Use Matlab7 programming, operate and we can obtain the membership degree matrix .

$$
\left[\begin{array}{lll}
1.0000 & 0.8549 & 0.3333 \\
0.3333 & 0.4633 & 1.0000 \\
1.0000 & 0.3333 & 0.4556 \\
0.3333 & 0.6048 & 1.0000
\end{array}\right]
$$

The weight set is as follows.

$$
S^{*}=(0.28380 .23290 .23190 .2513)
$$

According to formula (13), we can get the calculation. $\rho\left(S^{*}\right)=\left(\begin{array}{lll}0.6771 & 0.5798 & 0.6844\end{array}\right)$. Thus we have the order $B<A<C$. This order says the third scheme precede others. Above-mentioned results show that A scheme and ideal scheme (not exist actually ) are close most. It should be paid the utmost attention to while choosing the capital project

\section{IV.CONCLUSIONS}

This method result is on the basis of guaranteeing certain sensitivity and accuracy, the credibility is higher and easier to realize. It uses the weighted average comprehensive value to arrange in an optimized-select order to the capital project, and has overcome the one-sidedness that the single index was appraised in the past. It has offered a kind of method with practical science for investment decision of the electric project.

\section{REFERENCES}

[1] DENG Ju-long, Grey prediction and grey decision-making[M], Publishing house of Central China University of Science and Technology. 2002

[2] ZHANG Su, Assess on the threaten degree of goals on the basis of the grey related degree $[\mathrm{J}]$. Guidance and detonator. 2005, 26(3):19-24

[3] LI Deng-feng, CHENG Chun-tian, CHEN Shou-yu. Many goals decision-making methods with some information incomplete

[J]. Control and decision-making, 1998, 1(1): 83-86.

[4] NIU Xiao-dong, CAO Su-hua. Electric load prediction technology and application [M]. China Electric Power Publishing House, 1998.

[5] LI Ren-an, XIA-Lin. Appraise on the economic benefits of enterprise based on the grey related analysis $[\mathrm{J}]$. Operation research and management, 2001, 10(1): 139-141. 